Original Research Article

\title{
Introduction of a teaching module on intravenous drug administration and communication skills in pharmacology
}

\author{
Sangeeta Bhanwra*, Rajiv Kumar, Gaurav Garg
}

\begin{abstract}
Department of Pharmacology, Government Medical College and Hospital, Chandigarh, Punjab, India
\end{abstract}

Received: 26 May 2019

Revised: 10 June 2019

Accepted: 02 July 2019

\section{*Correspondence to: \\ Dr. Sangeeta Bhanwra, Email: doc_sangeeta@ yahoo.com}

Copyright: (C) the author(s), publisher and licensee Medip Academy. This is an openaccess article distributed under the terms of the Creative Commons Attribution NonCommercial License, which permits unrestricted noncommercial use, distribution, and reproduction in any medium, provided the original work is properly cited.

\begin{abstract}
Background: Pharmacology practicals mainly focus on increasing the knowledge component but teaching on psychomotor and soft skills is largely lacking. Teaching correct method of intravenous drug administration and the communication skills about drug therapy in Pharmacology practical classes can help in minimizing the errors in drug administration and improving the patient compliance and adherence to the therapy. Objectives of this study were teaching module on intravenous drug administration and communication skills to undergraduate students in Pharmacology and to evaluate the perceptions of students and teachers towards the new teaching module.

Methods: Correct methods of intravenous drug administration were demonstrated in practical classes. Role play was done to teach about communication skills regarding right method of using an inhaler and also about prescribing the correct dosage regimens. Perceptions of students and teaching staff members were collected on the teaching module.

Results: Almost all of the students $(>96 \%)$ were of the opinion that learning correct drug administration methods and communication skills was relevant to the future practice and $95 \%$ students felt that after the role play sessions, they were better equipped in communicating with the patients about the medication use and were in favour of teaching these to all the medical students.

Conclusions: Our study concludes that the teaching module on intravenous drug administration and communication skills was well accepted by both the teaching staff and the students and was found feasible and relevant to be introduced in the curriculum by both of them.
\end{abstract}

Keywords: Communication skills, Inhaler, Intravenous infusion, Mannequin arm, Role play, Undergraduates

\section{INTRODUCTION}

Pharmacology practical teaching has undergone a major change in the last few years. With the discontinuation of animal use, practicals mainly include computer simulation exercises for showing effects of drugs on various animal tissues and organs, along with identifying adverse drug reactions of a specific drug, prescription-interaction writing and prescription error analysis and all these are mainly knowledge based. Thus the students may acquire good knowledge, but they may lack psychomotor skills of correct methods of drug administration and also the soft skills related to communication and patient education about the use of medications.

A medication error is a failure in the treatment process that leads to or has the potential to lead to harm to the patient. ${ }^{1}$ Error can occur in administering or taking any medicine or dosage regimen. Poor prescribing is perhaps the most common cause of the preventable medication error. In a study, medication errors due to drug administration were found to be $15.34 \%$ of all the medication errors. ${ }^{2}$ Hence, it is the need of the hour that students are sensitized to the six 
rights-right medication, dose, time, patient, route, technique of medication preparation and administration during their initial years to minimize such medication errors. ${ }^{3}$

According to MCI regulations on Graduate Medical Education, the curriculum needs to be made competency based. ${ }^{4}$ It will be implemented in all the medical colleges in India from August 2019. Competency based curriculum can help to ensure that the medical graduate develops the ability to fulfill the health care need of the society. A study identified 40 competencies for a second professional student in Pharmacology, for example, to learn to identify the commonly used drug formulations, concept of National Medicine List, to calculate and administer accurate drug doses parenterally, be able to communicate with patients regarding correct methods of drug administration using special devices like inhalers etc. ${ }^{5,6}$ Hence, the present study was undertaken keeping these goal of teaching a second professional undergraduate student about the correct drug administration methods and communication skills regarding the drug use to avoid the medication errors as far as possible. In India, newer teaching-learning methodologies have been introduced in various medical colleges in the last decade. However, the change has not been substantial and needs to be explored further and implemented for better understanding and application of pharmacotherapeutics.

\section{METHODS}

The study was carried out in the department of Pharmacology and it involved the voluntary participation of Second Professional MBBS students. 85 out of 100 second professional students who attended all the sessions of new teaching module were included in the study. Sensitisation of students and teaching staff was done about the teaching module and its importance in a lecture. Written information about the module was also provided to the students. Written informed consent was taken from the students before starting the study.

In a practical batch of 50 students, students were further divided into small groups of 10 each. Three sessions of 2 hours each on correct intravenous drug administration methods based on WHO "Guide to good prescribing" were conducted. ${ }^{7}$ These included correct technique of aspiration of drug from a vial, reconstitution and aspiration of a drug in powdered form from a vial containing, calculation of drug dose for intravenous drug administration and setting up of an I/V drip with required drop rate on a mannequin arm. Videos on above techniques were also shown to the students. Role play was done to teach about communication skills regarding correct use of a metered dose inhaler and correct dosage regimens of OCP and ATT. Total two sessions of 2 hours each were conducted for each batch. Students were given time to practice these skills. The students were given feedback questionnaires (pre-validated by the medical education unit members of the Institute) to fill to know about their perceptions about the new teaching module (Table 1).
Table 1: Students' perceptions on teaching module on drug administration and communication skills.

\section{Questions}

Learning intravenous (I/V) drug administration and Communication skills is relevant to future practice

Teaching module on above skills was well planned and coordinated

I am more confident about I/V drug administration in future

After the role play sessions, I feel better equipped in communicating with the patients

I/V drug administration and communication skills should be taught to all the medical students

The teaching sessions increased my interaction with my teachers

The teaching methods used were beneficial in learning the practical skills

Found the teaching sessions on skills interesting

Time allocated was adequate

What do you think went well?

What do you think could be done differently?

In the questionnaire, for first nine questions, the rating was done on a five-point Likert scale of 1= "Strongly disagree" to $5=$ "Strongly agree" and there were two open ended questions. Teaching staff perceptions were collected on a feedback questionnaire pertaining to the usefulness, feasibility and about their opinion about implementation of new teaching module as a regular part of the curriculum (Table 2).

\section{Table 2: Perceptions of teaching staff members on teaching module on drug administration and communication skills.}

\begin{tabular}{l} 
Questions \\
Teaching module on correct drug administration \\
methods and communication skills will help in \\
improving learning skills \\
\hline Teaching module on skills is feasible to introduce \\
\hline The method is more time consuming \\
\hline It resulted in active participation of students \\
\hline $\begin{array}{l}\text { Students became more confident in demonstrating the } \\
\text { skills }\end{array}$ \\
\hline $\begin{array}{l}\text { Learning these skills will help in reducing the } \\
\text { medication errors }\end{array}$ \\
\hline $\begin{array}{l}\text { It should be incorporated in curriculum as a regular } \\
\text { future activity }\end{array}$ \\
\hline What do you think could be done differently?
\end{tabular}

It consisted of seven questions to be answered on 5 point Likert scale and one open ended question. In addition to the above, a checklist of correct steps of above taught skills was prepared and five stations for objective structured practical examination (OSPE) were set up in the next class. Five stations consisted of aspiration of drug from a vial (procedural station-5 min), calculation of dose of a drug and drip rate 
(response station-5 min), setting up of an intravenous drip on a mannequin arm (procedural-10 $\mathrm{min}$ ), communicating about the use of a metered dose inhaler (communication station$5 \mathrm{~min}$ ) and use of ATT by role play (communication station-5 $\mathrm{min}$ ). In the communication skills, students were assessed on communicating about the details of drug dosage and its side effects to the patients also. ${ }^{8}$ The trial run of OSPE with 10 students was done to check for its feasibility in this set up for future.

The study was approved by the Institutional Research and Ethics committees.

\section{RESULTS}

The students who participated in all the sessions were given feedback forms to fill at the end of sessions. Questionnaire consisted of nine questions based on 5-point Likert scale (strongly disagree, disagree, agree, neutral, strongly agree) and two open ended questions. The data so generated was analysed quantitatively using Microsoft office Excel. The open ended questions in feedback forms were analyzed qualitatively and important themes and suggestions were outlined (Figure 1, 2, 3).

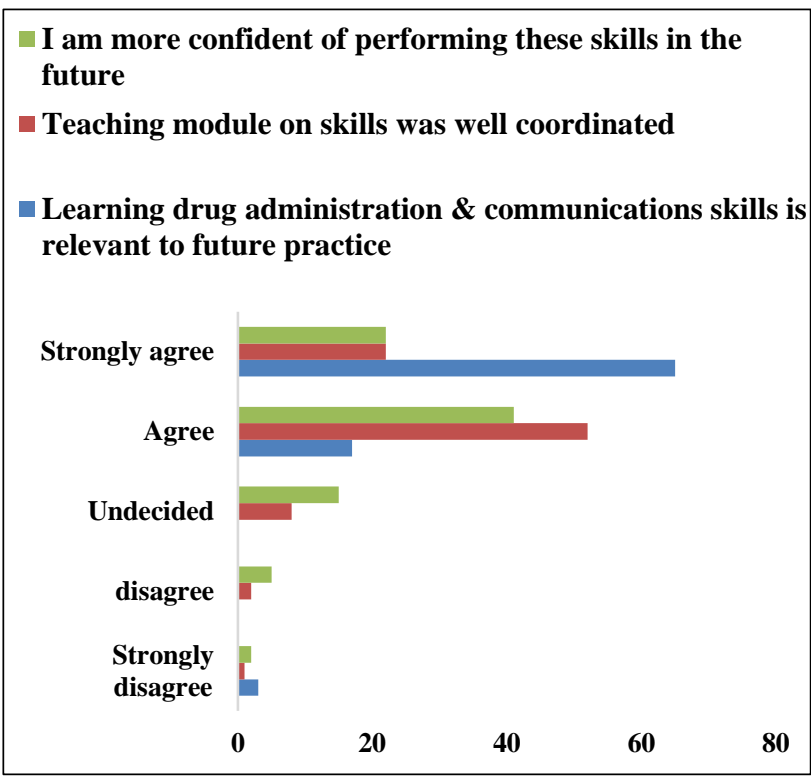

Figure 1: Responses of students on the questionnaire (Question Nos. 1-3).

Almost all the students (96\%) were of the opinion that learning correct drug administration methods and communication skills was relevant to the future practice. The teaching module used was found to be well planned by $97 \%$ of the students. $75 \%$ were feeling more confident in intravenous drug administration after the sessions and 95\% students felt that after the role play sessions, they were better equipped in communicating with the patients about the medication use. Almost all the students were in favour of teaching these to the medical students in $2^{\text {nd }}$ Professional MBBS. $78 \%$ students felt that the teaching module helped in improving their interaction with the teachers. Majority of students $(93 \%)$ were satisfied with the teaching methods used and $88 \%$ found the sessions interesting. $68 \%$ students found the time for the sessions on skills adequate.

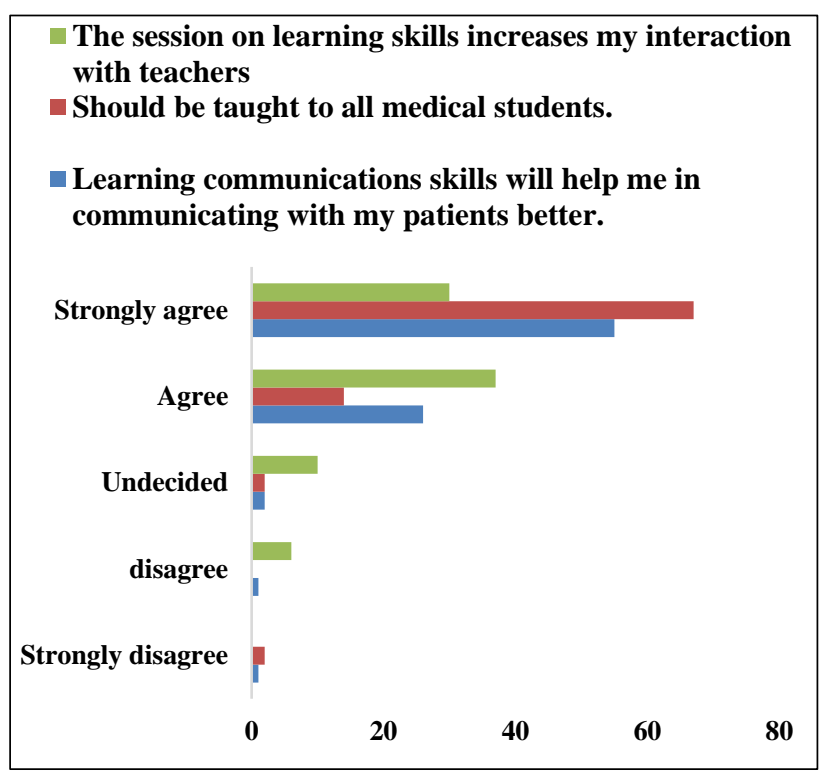

Figure 2: Responses of students on the questionnaire (Question Nos. 4-6).

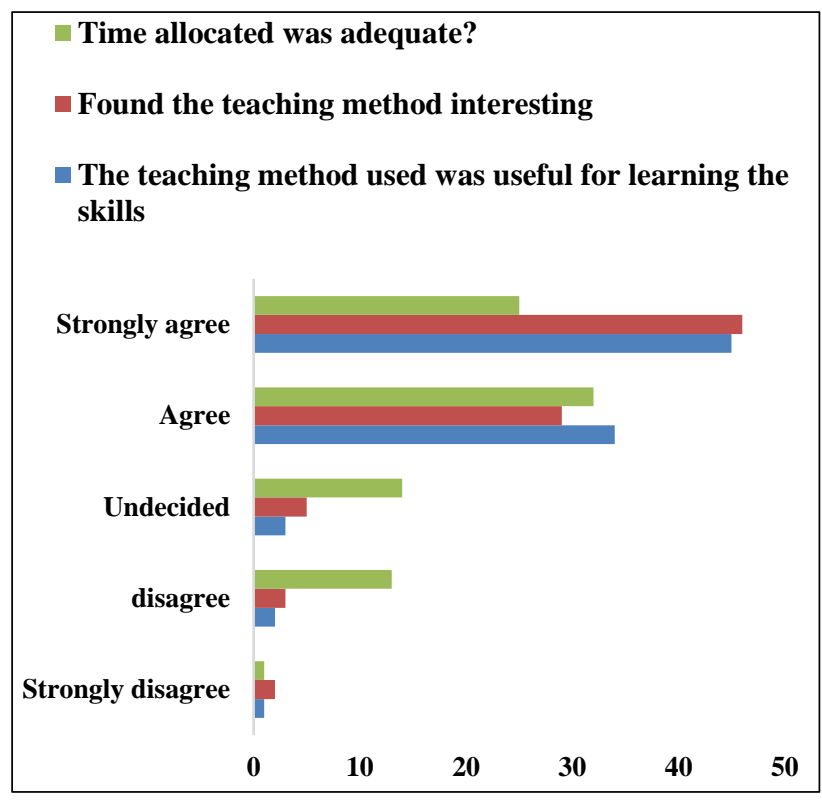

Figure 2: Responses of students on the questionnaire (Question Nos. 7-9).

Response of students to open ended questions in the feedback questionnaire and some suggestions were as follows

- This method of teaching should be a regular part of MBBS syllabus and should be taught more frequently. 
- Learning I/V administration will help us when we have to do it as interns. It will help us in taking blood samples also.

- These sessions should be conducted more often to do more practice.

- There should be incorporation of more such skill building practical exercises in syllabus.

- Time allocated for practicing and revising these skills should be more.

- Such clinical aspects should be covered more rather than demonstrations of practical on animals.

- Role play is a very good method for learning communication skills and each and every student should get a chance to show how to do it after learning it.

- Every student should get more time to practice.

\section{Response of teaching staff on feedback questionnaire}

All the teaching staff members who responded to the questionnaire provided were of the opinion that the teaching module on $\mathrm{I} / \mathrm{V}$ drug administration and communication about medication use will help in improving the learning of skills. They felt that it is feasible to be introduced and it should be a regular part of the pharmacology practical curriculum. Almost all of them felt that the teaching module will help in reducing the adverse drug reactions/mishaps due to medication use. They observed that the teaching module helped in increasing the confidence of students in demonstrating these skills. However, they felt that the time taken in practicing these procedures was more, and so they suggested that we should arrange for more infrastructure and equipments before starting it for the next batch. They also suggested that involvement of more teaching staff members in the process at a time will smoothen the process. They also were in the support of conducting assessment by OSPE for the next batch.

\section{Feasibility of conducting OSPE in the department}

With all the preparations including setting up of stations, timings and preparation of checklists, a trial run was conducted and it was seen that it was feasible to conduct OSPE in the department, instructions were well understood by the students and it could be completed in time also.

\section{DISCUSSION}

Author conducted this study on two components of this newly introduced teaching module. One was on intravenous drug administration and the second on communication skills about the medication use. This study showed that there was a consensus amongst students and teachers that the teaching module on intravenous drug administration and communication skills was relevant to future practice and it should be a regular part of the curriculum. With more than $90 \%$ of students agreeing about the benefits of training sessions, results were comparable to study findings by Tayem et al. ${ }^{8}$ Teachers were also in agreement with the fact that teaching such skills was important to prevent and reduce the adverse events due to drugs.

It has been seen over time that medication errors can happen during any stage of the treatment process, right from the basic prescribing, compounding or manufacturing, to dispensing of the drug, administration, and monitoring of therapy. These errors have always been significant causes of mortality. Various studies reported intravenous (IV) drugs being most commonly associated with drug administration errors. ${ }^{9,10}$ Incorrect dilutions and wrong IV infusion speed, improper dose or strength, wrong drug, wrong dosage form, wrong duration, and time are the various forms of drug administration errors that occur during parenteral administration. ${ }^{11}$ Hence, training medical students during their initial years is crucial to minimize such medication errors and the same has been accepted by this study participants. Beside this, they also felt the need for proper communication about the disease and drug therapy for patients' safety. In a study conducted about the awareness about drug therapy, it was reported that a significant number of patients had no information about the adverse reactions of their medications and warnings. ${ }^{12}$ In another study, it was found that training about communication skills is often lacking and that further endorses the results of this study about need of imparting these skills to the students in their formative years. ${ }^{13}$ It has been correctly stated by Manias, "Medication communication is a vital component of patient safety, quality of care, and patient and family engagement". ${ }^{14}$

In this regard, the role play demonstrations to teach them the communication skills were well accepted by the students and they felt that this approach enhanced their ability to explain drug therapy to a patient. These results are in accordance with the findings of Milles et al, who found in the study that most students had positive feelings about the role play sessions.

However, there were some limitations of this study. All the 100 students didn't attend all the sessions. Time period for the study was short with one batch, so limited practice sessions could be conducted after their syllabus completion. Assessment of all the students couldn't be done on the new teaching module. Only trial run of OSPE could be done, again due to paucity of time and less infrastructure (mannequin arms etc).

\section{CONCLUSION}

This study concludes that the teaching module on intravenous drug administration and communication skills was well accepted by both the faculty and the students and was found feasible and relevant to be introduced in the curriculum by both of them. After the sessions, the students became more confident about performing intravenous administration and communicating with the patients about the drug therapy. The faculty also accepted that it will help in reducing the mishaps due to drug administration. In view of above results, it is the 
need of the hour that the teaching module should be added in the pharmacology practical classes. Further, the assessment of students should be done on the same and the outcome will also help in deciding about including these sessions in the curriculum.

\section{ACKNOWLEDGEMENTS}

I (Dr. Sangeeta Bhanwra) wish to extend my gratitude towards the faculty of Christian Medical College, Ludhiana, who guided me about this project during my Advanced Course in Medical Education (ACME). The authors are highly thankful to $2^{\text {nd }}$ Prof MBBS students who participated in the study. Our special thanks are due to Dr. Darshpreet Singh (ex-demonstrator), Dr. Harmanjot Singh (demonstrator) and Dr. Anoop Singh (laboratory staff member) for their constant help.

Funding: No funding sources Conflict of interest: None declared

Ethical approval: The study was approved by the Institutional Ethics Committee

\section{REFERENCES}

1. Aronson JK. Medication errors: What they are, how they happen, and how to avoid them. QJM. 2009;102(8):513-21.

2. Likic R, Maxwell SR. Prevention of medication errors: Teaching and training. Br J Clin Pharmacol. 2009;67(6):656-61.

3. Devi V, Upadhye P, Ram P, Menezes RG. Development of a teaching module for parenteral drug administration and objective structured practical examination stations in pharmacology. Ind $\mathbf{J}$ Pharmacol. 2013 Nov;45(6):587-92.

4. Vision 2015. Published by Medical Council of India. Published in March 2011. Available at https://old.mciindia.org/tools/announcement/MCI_book let.pdf.

5. Midlöv P, Höglund P, Eriksson T, Diehl A, Edgren G. Developing a competency-based curriculum in basic and clinical pharmacology-a Delphi study among physicians. Basic Clin Pharmacol Toxicol. 2015 Dec;117(6):413-20.

6. Shah N, Desai C, Jorwekar G, Badyal D, Singh T. Competency based medical education: An overview and application in Pharmacology. Indian J Pharmacol. 2016;48(7):S5-9.

7. De Vries TP, Henning RH, Hogerzeil HV, Fresle DA, Policy M. World Health Organization. Guide to good prescribing: a practical manual. Geneva: World Health Organization. 1994;70-5.

8. Tayem YI, Altabtabaei AS, Mohamed MW, Arrfedi MM, Aljawder HS, Aldebous FA, et al. Competence of medical students in communicating drug therapy: Value of role-play demonstrations. Indian $\mathbf{J}$ Pharmacol. 2016 Jan;48(1):37-41.

9. Chua SS, Tea MH, Rahman MH. An observational study of drug administration errors in a Malaysian hospital (study of drug administration errors). J Clin Pharm Ther. 2009 Apr;34(2):215-23.

10. McDowell SE, Ferner HS, Ferner RE. The pathophysiology of medication errors: how and where they arise. Br J Clin Pharmacol. 2009 Jun;67(6):605-13.

11. McBride-Henry K, Foureur M. Medication administration errors: understanding the issues. Aust $\mathbf{J}$ Adv Nurs. 2006 Mar;23(3):33-41.

12. Singh J, Singh N, Kumar R, Bhandari V, Kaur N, Dureja S. Awareness about prescribed drugs among patients attending Out-patient departments. Int J App Basic Med Res. 2013 Jan;3(1):48-51.

13. Choudhary A, Gupta V. Teaching communications skills to medical students: Introducing the fine art of medical practice. Int J App Basic Med Res. 2015 Aug;5(Suppl 1):S41-4.

14. Manias E. Medication communication: A concept analysis. J Adv Nurs. 2010;66(4):933-43.

Cite this article as: Bhanwra S, Kumar R, Garg G. Introduction of a teaching module on intravenous drug administration and communication skills in pharmacology. Int J Basic Clin Pharmacol 2019;8:1825-9. 